\title{
SPEEDING UP INNOVATION PROCESSES IN AGRICULTURAL ENGINEERING THROUGH USER-CENTRED DESIGN AND MULTI-ACTOR APPROACH
}

\author{
Hannu E.S. Haapala \\ Agrinnotech, Finland \\ hannu.haapala@agrinnotech.com
}

\begin{abstract}
Innovation processes in agricultural engineering face factors that slow down or even abort them. This is the case also for the application and embedding phases. If not widely applied in practice, the innovations do not give their full potential. If the process is totally aborted, all the investments in research and prototyping are done in vain, and the projected benefits of the new solutions are not realized at all. To avoid unnecessary losses, it is important that users accept the developed products. The technologies need first to be purchased, and then used in a proper manner so that their benefits are realized, so that the users return to buy again. According to recent research, an important buying criterion of new solutions in agriculture is usability. Usable products have a good combination of ease-of-use, learnability, and efficiency. They also operate with few errors. Finally, they are subjectively pleasing. User-Centred Design (UCD) is a methodology for designing usable technologies and services. It is widely utilized to ensure better end-user acceptance. Inclusion of end-users in innovation makes the products more suitable for the users' variable situations. UCD also builds the users' trust on the solutions. Eventually, UCD reduces the need for iteration in the process, thus speeding up the innovation. Multi-Actor Approach (MAA) brings different kinds of people together to develop solutions. Best results are achieved when the participants have long enough cognitive distances. MAA speeds up the innovation processes as the products have been assessed from several angles. The probability for reaching a winning product arises. In the paper examples are given on UCD and MAA in the design of agricultural solutions. Two projects of the author, an OECD-CRP and an H2020 funded research on how to speed up and support innovation in agriculture, are referred. Recommendations on how to enhance the usage of these methods are given.
\end{abstract}

Keywords: agriculture, engineering, innovation, User-Centred Design, Multi-Actor Approach.

\section{Introduction}

The paper concentrates on how to effectively speed up innovation in agriculture. Innovation processes tend to be driven by engineers and designers and the end-users are not actively involved. Consequently, innovations face factors that slow down or even abort them.

According to Schumpeter [1-2] innovations are real only if they are widely adopted and the users get significant benefits when using them. Otherwise they are merely minor improvements or too local to be called real innovations. In agriculture, there are a large variety of innovation types and, accordingly, different challenges to be tackled [3-4]. In this study the main focus is set on real technological innovations in agriculture.

Generally speaking, if new beneficial technologies do not reach the level of real innovations, they cannot reach their full potential. This causes lots of losses:

- The work and funds invested in the research and development are just costs.

- Users do not get their full benefits (e.g. better economics, sustainability of operation, ease of work, reduced risks).

- The society does not benefit (e.g. quality and quantity of products, reduced environmental load, sustainability of production).

To avoid these unnecessary losses, it is important that users swiftly accept the developed products. As new technologies are applied, the users first need to trust in their potential [5]. Lack of trust can slow down the adoption. Trust building takes time, as the new developments need to compete successfully with the traditional ones. Pioneer users first try out the products and only after a period of success others join using them.

Jacob Nielsen [6] divides system acceptability to social and practical. Even if the system is socially acceptable, it also needs to fulfil practical requirements, e.g. moderate cost, compatibility with existing systems, and adequate reliability. On top of these, the system must be useful. Usefulness consists of two branches, usability and utility. Utility is about whether the system enables the user to do as intended. Usability is about how well, or easy, the user can achieve that goal. (Fig. 1) 
According to recent research [7-9], usability is a central challenge of new solutions in agriculture. Usable products have [6] (Fig. 1) a good combination of ease-of-use, learnability, and efficiency. They also operate with few errors. Finally, they are subjectively pleasing. Consequently, usability is an important buying criterion of technologies.

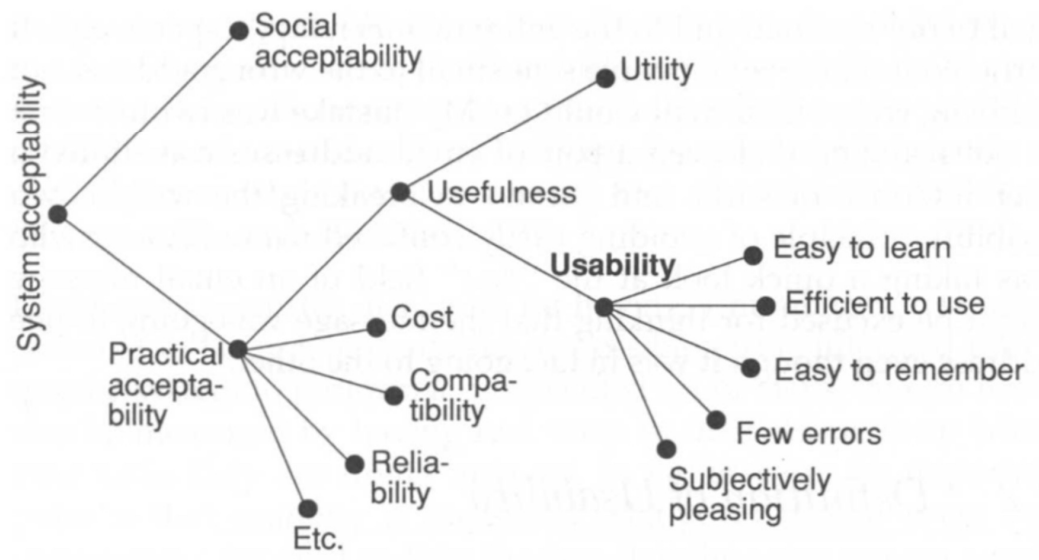

Fig. 1. Model of parts of system acceptability [6]

User-Centred Design (UCD) [6] is a methodology for designing usable technologies and services. It is widely utilized to ensure better end-user acceptance. Inclusion of end-users in innovation makes the products more suitable for the users' variable situations. The UCD also builds the users' trust on the solutions. Eventually, UCD reduces the need for iteration in the innovation process, thus speeding up the innovation.

Multi-Actor Approach (MAA) [10] brings different kinds of people together to develop solutions. Best results are achieved when the participants have long enough cognitive distances. In MAA partners with complementary types of knowledge - scientific, practical and other - join forces in the project activities from beginning to end. MAA speeds up the innovation processes as the products have been assessed from several angles. The probability for reaching a winning product arises.

\section{Materials and methods}

In 2011-2013 a research project 'Sustainable Precision Farming through User-Centered Design' was initiated. OECD-Cooperative Research Programme funded the project. The aim was to find new insights on how to speed up innovation in Precision Farming (PF) and equal high-tech in agriculture. To start with a web-based questionnaire was sent to 200 selected recipients around the world using LinkedIn. As the questionnaire was wide and it took almost an hour to answer, only 41 complete replies were achieved. Thereafter 10 in-depth face-to-face interviews of selected experts were done. Webropol ${ }^{\mathrm{TM}}$ software was used for the questionnaire. The respondents' competence profile was variable. They were strong in engineering, research and practical use of technologies at the farm level. Weeknessess were found in skills in marketing, sales, and teaching of design.

The questionnaire had three main parts: assessing the current PF technology, the application rate of PF technology, and the acceptability as a challenge in PF. Furthermore, the responders were asked to tell what they thought about the applicability of UCD as a methodology to enhance innovation in agricultural engineering. The experts also gave their opinions and visions of the most important research and development topics of UCD in agricultural engineering. Finally, they rated the importance and urgency of UCD and PF related actions in research policy.

Another related project, "AgriSpin" (2015-2017), was funded by the EU research and innovation program Horizon 2020. In AgriSpin, there were 15 participating partner organizations from 12 countries. The objective of AgriSpin was to systematically explore Innovation Support Service Providers (ISSPs) in agriculture and rural development across Europe. The overall goal was to help create a stimulating environment for innovations.

Cross Visit Methodology [11] including thorough analysis of 57 innovation cases in 15 countries in Europe was applied and improved during the project. The Spiral of Innovation was used to illustrate 
the cases and to communicate them to wider audience. Pearls, Puzzlings and Proposals were reported for each case in Final Symposiums, where relevant stakeholders were informed about the findings and challenged for developing the local innovation environment of agriculture.

\section{Results and discussion}

In the project 'Sustainable Precision Farming through User-Centered Design' the expert evaluations confirmed the proposed model for successful innovation. The technologies need first to be purchased, and then used in a proper manner so that their benefits are realized. Only realized benefits make the users return to buy again [8]. (Fig. 2)

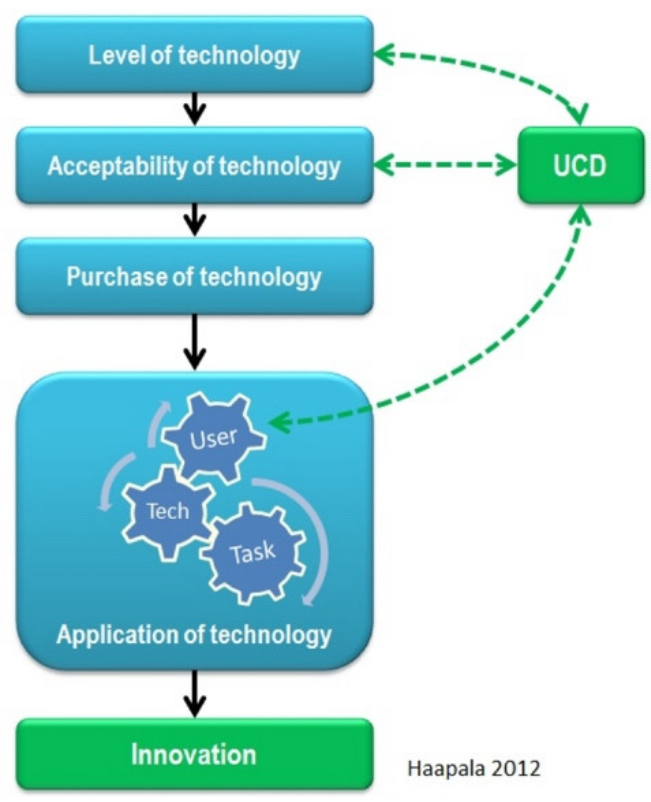

Fig. 2. Confirmed model of real innovation. Acceptable high-level technologies are bought and taken into practical use. Correct application realises the benefits and makes users buy again. Wide adoption eventually makes real innovation. User-Centred Design supports the process [8]

The experts agreed that:

- Innovations need to be completed, e.g. they need to be spread and used by a wide user audience;

- The most important obstacles for quick innovations are: lack of trust in a new technology among farmers, bad usability of new technologies due to absence of User-Centred Design in the education of engineers and designers, omitting users in the innovation process;

- User-Centered Design is the key for better acceptance of innovations.

Further work should be carried out to better understand the elements of an effective user-centred R\&D process, the users' processes, and how acceptability is enhanced (Fig. 3) [8].

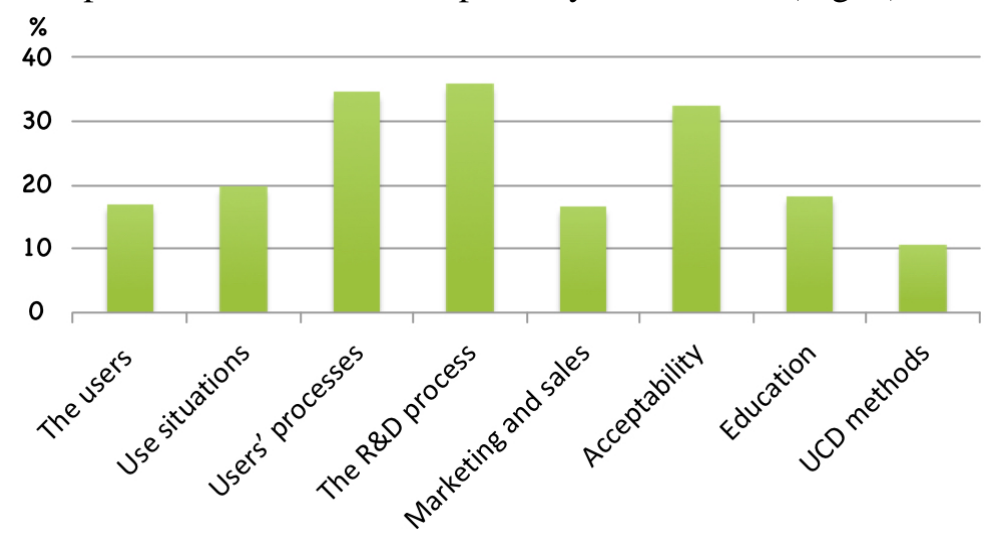

Fig. 3. Experts' suggestions on topics for further studies [8] 
In the project "AgriSpin" the Cross Visit method was further developed. The resulting method included a three to four day visit of 6-8 experts evaluating the innovation case and related Innovation Support Service Providers (ISSPs). The Spiral of Innovations was further developed to easily illustrate the important phases, where actions can be taken to enhance the speed of innovation [11]. (Fig. 4)

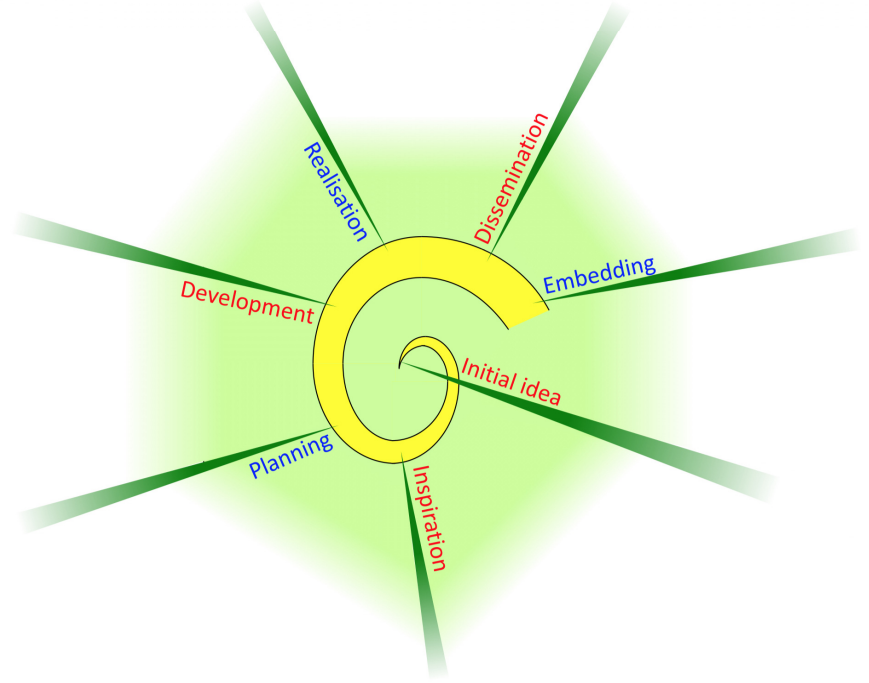

Fig. 4. Spiral of innovations [11]

An example of a filled spiral from a Cross Visit shows how the factors and actors affecting each phase were illustrated [12]. (Fig. 5)

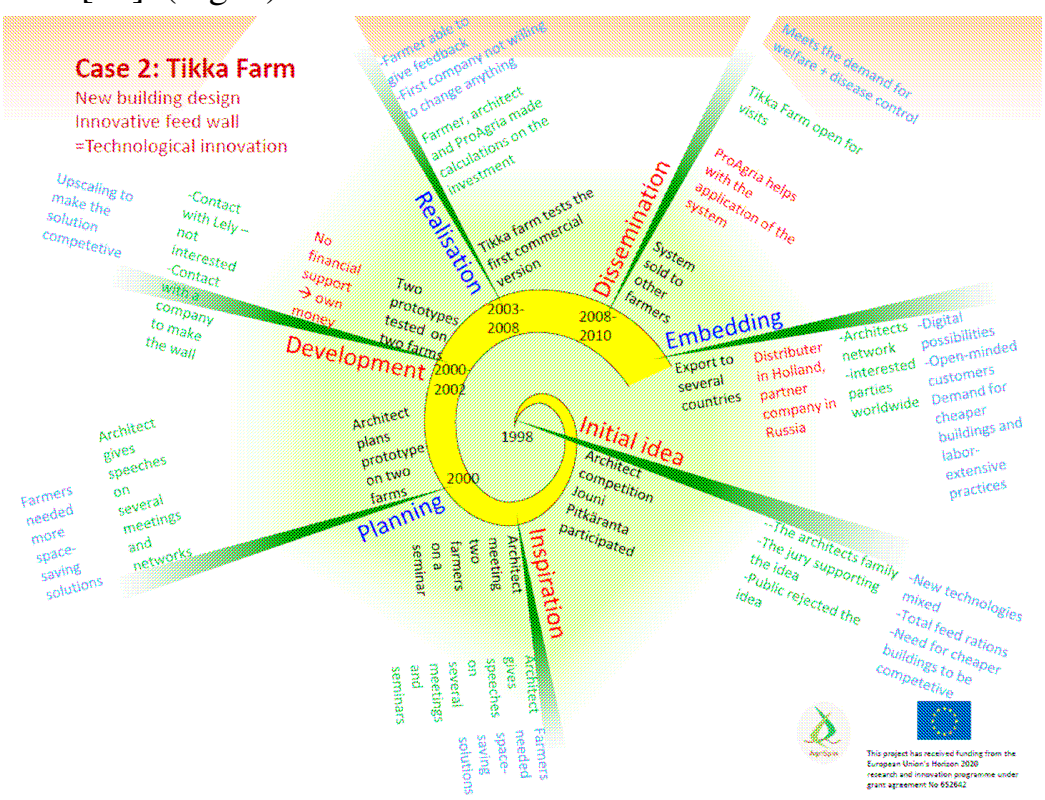

Fig 5. Spiral of Innovations from Tikka Farm, Finland. Actors and factors affecting the innovation, the feeding wall (a new building design), are added for further discussion and analysis [12)

The main observations and suggestions from the 57 Cross Visits were [13]:

- There are societal challenges limiting the acceptance and take-up of innovations;

- Multi-Actor-Approach should be applied to cover the needed expertise;

- Supporting actions are needed: advisory, research, consultation, authorities, funding;

- Free actors (independent, trustworthy and passionate individuals) are important for a successful innovation process.

The results are in line with the latest research and guidelines on agricultural innovations. Adoption has been slow. Systemic thinking, instead of the traditional linear innovation model, is 
required. Increased user-interaction would be beneficial. Innovation brokers and free actors are needed [14-17].

\section{Conclusions}

The results challenge the traditions of agricultural R\&D. Traditionally, engineers and designers have led the R\&D processes in agriculture. The users have been involved quite late when products are already at prototype level. Usability issues have arisen because of poor knowledge of actual user needs and use situations. Consequently, adoption of the newest technologies has been slow.

The results give new insights about the increased need of user interaction in $R \& D$ of agricultural technologies and services.

Conclusions of 'Speeding up innovations in agriculture' pointed out important hinders of effective innovation in agricultural engineering. Poor adoption includes mainly problems in acceptability. Inside the broad topic of acceptability usability issues are the most important ones slowing down innovation in agriculture. Farmers face problems in integrating the new technologies in the existing systems at the farm level. They have mistrust on new technology as a whole.

To tackle the acceptance challenges, the education of engineers, designers, marketers and endusers of automation needs to include more user-centred elements. They also need to interact better during the R\&D process. User-Centred Design (UCD) is recommended as a potential method to overcome most of the acceptability issues in innovation processes.

Agricultural innovations, although technological in nature, are developed, realized, disseminated and embedded through a social process. This process should be better understood to be able to support it. Multi-Actor Approach is needed since the application environment of agriculture is complex. Supporting actions that build on actual end-user requirements need to be introduced.

New kinds of advisory and consultation services that cope with the systems level challenges are to be introduced. Educational needs of all actors involved in the innovation process need to be met. Experimental culture is needed. Demonstrations, Living Labs and ad hoc user networks have a central role in this development.

The Innovation Support Service Providers (ISSPs) should form and maintain networks with practitioners for the long-term survival of innovations. In this work, soft skills such as communication, negotiation, networking and cooperation are increasingly important. Responsiveness, empathy and awareness create conditions of social embedding. Furthermore, the role of funders is important in creating an enabling environment for both ISSP's and innovators.

\section{Acknowledgements}

OECD Co-operative Research Programme funded the "Speeding up innovation in agriculture" project. The "AgriSpin" was funded by the EU Research and Innovation programme Horizon 2020.

\section{References}

[1] McCraw T. Prophet of Innovation: Joseph Schumpeter and Creative Destruction. Cambridge: Harvard University Press, 2010, 719 p.

[2] Ina D. Identifying innovation in surveys of services: a Schumpeterian perspective. http://dx.doi.org/10.1016/j.respol.2003.07.004. In: Research Policy. Elsevier. Vol. 33, 3: 2004, pp. 551-562.

[3] Knierim A., Koutsouris A., Mathe S., Ndah H.T., Temple L., Tromphe B., Wielinga E. Support to innovation processes: a theoretical point of departure: WP1 deliverable 1.1: report of the AgriSpin project. University of Hohenheim, Germany, 2015. [online][16.02.2019] Available at: http://agrispin.eu/wp-content/uploads/

2016/01/Theoretical-Framework-of-AgriSpin.pdf. Last accessed 29/03/19.

[4] Klerkx L., Van Mierlo B., Leeuwis. C. Evolution of systems approaches to agricultural innovation: concepts, analysis and interventions. Farming Systems Research into the 21st century: The new dynamic, Springer, 2012, pp. 457-483. 
[5] Li W., Hess T., Valacich J. Why do we trust new technology? A study of initial trust formation with organizational information systems. The Journal of Strategic Information Systems. http://dx.doi.org/10.1016/j.jsis.2008.01.001. Elsevier. Vol 17, 1: 2008, pp. 39-71.

[6] Nielsen J. 1993. Usability Engineering. Academic Press Inc. 362 p.

[7] Haapala H., Nurkka P. Usability as a Challenge in Precision Agriculture - case study: an ISOBUS VRT. Agric. Eng. International: the CIGR Ejournal, 2006, 9 p.

[8] Haapala H. The potential of User-Centered Design (UCD) to make radical agricultural innovations. Int. Conference of Agricultural Engineering - CIGR-AgEng 2012: Agriculture and Engineering for a Healthier Life, Valencia, Spain, 8-12 July 2012. p. C-0094

[9] Haapala H. Speeding up innovation in agricultural IT. Journal of Agricultural Engineering. Vol XLIV. 2013, pp. 137-139.

[10] Anon. 2019. EIP-AGRI Brochure Horizon 2020 multi-actor projects. [online][29.03.2019] Available at: https://ec.europa.eu/eip/agriculture/en/publications/eip-agri-brochure-horizon-2020multi-actor.

[11] Wielinga E., Paree P. AgriSpin cross visit manual: Space for innovations in Agriculture. 10th ed. 2016. [online][29.03.2019] Available at: http://agrispin.eu/wp-content/uploads/2016/11/CrossVisits_Improved-Methodolog-1.pdf.

[12] Haapala H. Report: Cross Visit in Finland June 13-16 2016. Manuscript for an internal report of AgriSpin.

[13] Anon 2019. AgriSpin D1.3: Synthesis report on selected and documented innovation cases for Cross Visits. [online][29.03.2019] Available at: https://agrispin.eu/wp-content/uploads/2016/10/ Synthesis_report.pdf.

[14] Winstead A., Norwood S., Griffin T., Runge M., Adrian A., Fulton J., Kelton J. Adoption and Use of Precision Agriculture Technologies by Practitioners. In: Proc. 10th International Conference on Precision Agriculture, 18-21 July 2010. Denver, Colorado

[15] Klerkx L., Hall A., Leeuwis C. Strengthening agricultural innovation capacity: Are innovation brokers the answer? International Journal of Agricultural Resources, Governance and Ecology, 8 , 2009, pp. 409-438.

[16] Knickel K., Brunori G., Rand S., Proost J. Towards a better conceptual framework for innovation processes in agriculture and rural development: From linear models to systemic approaches. The Journal of Agricultural Education and Extension, 15. 2009, pp. 131-146.

[17] Oslo Manual 2018: Guidelines for Collecting, Reporting and Using Data on Innovation. 4th Edition. The Measurement of Scientific, Technological and Innovation Activities. OECD Publishing, Paris/Eurostat. [online][29.03.2019] Available at: https://doi.org/10.1787/9789264304604-en. 